\title{
Postannealing Effect at Various Gas Ambients on Ohmic Contacts of Pt/ZnO Nanobilayers toward Ultraviolet Photodetectors
}

\author{
Chung-Hua Chao, ${ }^{1}$ Mao-Yi Chen, ${ }^{1}$ Chii-Ruey Lin, ${ }^{1}$ Yueh-Chung Yu, ${ }^{2}$ \\ Yeong-Der Yao, ${ }^{2}$ and Da-Hua Wei ${ }^{1}$ \\ ${ }^{1}$ Institute of Manufacturing Technology and Graduate Institute of Mechanical and Electrical Engineering, \\ National Taipei University of Technology, Taipei 106, Taiwan \\ ${ }^{2}$ Institute of Physics, Academia Sinica, Taipei 115, Taiwan
}

Correspondence should be addressed to Yueh-Chung Yu; phycyu@phys.sinica.edu.tw and Da-Hua Wei; dhwei@ntut.edu.tw

Received 20 September 2013; Accepted 18 November 2013

Academic Editor: Teen-Hang Meen

Copyright (C) 2013 Chung-Hua Chao et al. This is an open access article distributed under the Creative Commons Attribution License, which permits unrestricted use, distribution, and reproduction in any medium, provided the original work is properly cited.

\begin{abstract}
This paper describes a fabrication and characterization of ultraviolet (UV) photodetectors based on Ohmic contacts using Pt electrode onto the epitaxial $\mathrm{ZnO}$ (0002) thin film. Plasma enhanced chemical vapor deposition (PECVD) system was employed to deposit $\mathrm{ZnO}(0002)$ thin films onto silicon substrates, and radio-frequency (RF) magnetron sputtering was used to deposit $\mathrm{Pt}$ top electrode onto the $\mathrm{ZnO}$ thin films. The as-deposited $\mathrm{Pt} / \mathrm{ZnO}$ nanobilayer samples were then annealed at $450^{\circ} \mathrm{C}$ in two different ambients (argon and nitrogen) to obtain optimal Ohmic contacts. The crystal structure, surface morphology, optical properties, and wettability of $\mathrm{ZnO}$ thin films were analyzed by X-ray diffraction (XRD), field emission scanning electron microscopy (FE-SEM), atomic force microscopy (AFM), photoluminescence (PL), UV-Vis-NIR spectrophotometer, and contact angle meter, respectively. Moreover, the photoconductivity of the $\mathrm{Pt} / \mathrm{ZnO}$ nanobilayers was also investigated for UV photodetector application. The above results showed that the optimum $\mathrm{ZnO}$ sample was synthesized with gas flow rate ratio of $1: 3$ diethylzinc $\left[\mathrm{DEZn}, \mathrm{Zn}\left(\mathrm{C}_{2} \mathrm{H}_{5}\right)_{2}\right]$ to carbon dioxide $\left(\mathrm{CO}_{2}\right)$ and then combined with Pt electrode annealed at $450^{\circ} \mathrm{C}$ in argon ambient, exhibiting good crystallinity as well as UV photo responsibility.
\end{abstract}

\section{Introduction}

It is known that only ultraviolet A (UVA) with wavelength ranging from 320 to $400 \mathrm{~nm}$ of the sunlight can pass through the atmosphere and reach the earth's surface. The UVA might harm human's skin, and therefore it is an important issue to develop ultraviolet (UV) photodetector in the UVAwavelength region. Many wide band gap materials such as $\mathrm{GaN}, \mathrm{AlGaN}, \mathrm{ZnSe}$, and diamond have been used for the UV photodetector applications [1-6]. Compared with the above materials, zinc oxide $(\mathrm{ZnO})$ is considered as potential candidate compound for UV detector owning to its wide direct band gap of $3.37 \mathrm{eV}$ at room temperature, relatively large exciton binding energy of $60 \mathrm{meV}$, nontoxicity, outstanding thermal and chemical stability, and low power threshold for optical pumping as well as rich raw materials $[7,8]$. However, due to the challenge of p-type doping in $\mathrm{ZnO}$ structures, fabrication of $\mathrm{ZnO} \mathrm{p}$ - $\mathrm{n}$ junction based on UV photodetector is still under development [9]. Hence, either Ohmic contact based photoconductive type or Schottky contact based photovoltage type of $\mathrm{ZnO}$ metalsemiconductor-metal (MSM) is another way to develop UV photodetector $[10,11]$. Comparing the differences between Ohmic and Schottky contact types, the Ohmic contact based photoconductive type device is typically more easily made and more understood. High quality $\mathrm{ZnO}$ films with good Ohmic contact are essential for fabricating high performance UV photodetector, which is based on a strong oxygen chemisorption and photodesorption mechanism on both the grain boundaries and surface $[12,13]$.

Over the past few decades, various growth techniques of stoichiometric $\mathrm{ZnO}$ phase have been used, such as thermal 
evaporation, radio-frequency (RF) magnetron sputtering, pulsed laser deposition (PLD), molecular beam epitaxy (MBE), metal organic chemical vapor deposition (MOCVD), and plasma enhanced chemical vapor deposition (PECVD) [14-18]. Among these techniques, the PECVD system is a promising one for fabricating large-area uniform $\mathrm{ZnO}$ thin films in order to apply for future electronic devices and sensors because it has numerous advantages, namely, low cost and high growth rates. On the other hand, the plasma bombardment can increase the density of thin films and enhance the ion decomposition reaction rate, which was used to improve the thin films crystallinity [19]. Thus, the PECVD system was used to grow $\mathrm{ZnO}$ thin films onto silicon substrates with various gas flow rate ratios of diethylzinc $(\mathrm{DEZn})$ to carbon dioxide $\left(\mathrm{CO}_{2}\right)$ and at a fixed temperature of $400^{\circ} \mathrm{C}$ in this presented work. On the other hand, there are some reports on Ohmic contacts of $\mathrm{ZnO}$-based devices using $\mathrm{ZrB}_{2} / \mathrm{Pt} / \mathrm{Au}$, Ti/Au, $\mathrm{Pt} / \mathrm{Ni} / \mathrm{Au}$ or $\mathrm{Ni} / \mathrm{Pt}$, and so forth as the contact-electrode metals [20-23]. Due to high thermal and electrical conductivity, good temperature and chemical stability, platinum $(\mathrm{Pt})$ is a better material for electrode application. Herein, Pt as electrode material of Ohmic contact was used to deposit onto $\mathrm{ZnO}$ films by $\mathrm{RF}$ magnetron sputtering.

However, there is little report on the effects of postannealing on electrical properties of $\mathrm{Pt} / \mathrm{ZnO}$ contacts through deposition of epitaxial $\mathrm{ZnO}$ films onto Si substrates. In addition, Pt metal forms an Ohmic contact with n-type $\mathrm{ZnO}$. Thus, $\mathrm{ZnO} / \mathrm{Pt}$ heterostructures could offer a range of advantages for the realization of optoelectronic devices such as UV photodetectors. The electrical properties of $\mathrm{Pt} / \mathrm{ZnO}$ film contacts are a key to the use of $\mathrm{ZnO}$ films in such devices, and a study of such properties is vital in determining the potential of such heterostructure for device applications. The main aim of the present paper is to systematically study the effects of different gas flow rate ratios of $\mathrm{DEZn}$ to $\mathrm{CO}_{2}$ on crystalline quality and uniformity of epitaxial $\mathrm{ZnO}$ films, modification of native defects in $\mathrm{ZnO}$ films, and the electrical properties of $\mathrm{Pt} / \mathrm{ZnO}$ nanobilayer films contact and explore the potential application of UV photodetector. This presented study was separated into two parts. The first part was the synthesis of epitaxial $\mathrm{ZnO}$ films on silicon substrates by PECVD system with various $\mathrm{CO}_{2}$ flow rates. The second part was the deposition of $\mathrm{Pt}$ to form Ohmic contacts onto $\mathrm{ZnO}$ films by RF magnetron sputtering. The standard liftoff process was used to fabricate the UV detectors with interdigitated electrodes. Furthermore, the as-prepared UV devices were postannealed via rapid thermal annealing (RTA) at various temperatures and with different ambients (argon and nitrogen) to obtain Ohmic contacts. The crystalline structure, surface morphology, optical properties, and wettability of $\mathrm{ZnO}$ thin films were investigated by $\mathrm{X}$-ray diffraction (XRD), field emission scanning electron microscopy (FESEM), atomic force microscopy (AFM), room temperature photoluminescence spectra (PL), and contact angle meter, respectively. $I-V$ curves were used to determine the Ohmic contacts efficiency. Finally, the photoresponse of the devices at room temperature in air was discussed.

\section{Experimental Procedures}

$\mathrm{ZnO}$ thin films were deposited on silicon (100) substrates employing PECVD system, which used diethylzinc [DEZn, $\mathrm{Zn}\left(\mathrm{C}_{2} \mathrm{H}_{5}\right)_{2}$ ] and carbon dioxide $\left(\mathrm{CO}_{2}\right)$ gas as precursors for supplying zinc and oxygen sources, respectively. The $15 \mathrm{~cm}$ diameter showerhead served as the top electrode and was connected with a $13.56 \mathrm{MHz}$ radio-frequency $(\mathrm{RF})$ power that could generate the plasma through a match network. The bottom electrode was grounded and served as the sample stage. The distance between top electrode and bottom electrode was fixed at $30 \mathrm{~mm}$. All the $10 \mathrm{~mm} \times 10 \mathrm{~mm}$ silicon substrates were cleaned by using acetone, alcohol, and de-ionized water, for half an hour in an ultrasonic cleaner. The system was evacuated to base pressure at $3 \times 10^{-6}$ Torr by rotary pump and turbo pump, respectively. Subsequently, the argon plasma induced from RF generator in the chamber was used to clean the substrate surface oxide layer for 15 minutes. The working pressure of the chamber was kept at 6 Torr and RF power was fixed at $70 \mathrm{~W}$, and the substrates were heated at $400^{\circ} \mathrm{C}$ during $\mathrm{ZnO}$ thin films growth. A series of $\mathrm{ZnO}$ thin films with the fixed thickness of $500 \mathrm{~nm}$ were synthesized on the silicon substrates with different gas flow rate ratios of DEZn to $\mathrm{CO}_{2}$ $(1: 1,1: 2$, and $1: 3)$. Crystalline structure of $\mathrm{ZnO}$ thin films was characterized by X-ray diffraction (XRD) with $\mathrm{Cu} \mathrm{K}_{\alpha}$ radiation $(\lambda=1.54 \AA)$. The surface morphology of $\mathrm{ZnO}$ films was observed by field emission scanning electron microscopy (FE-SEM). The surface topography and roughness of thin films were further analyzed from the atomic force microscope (AFM). Photoluminescence (PL) was carried out at room temperature to study the optical properties of the $\mathrm{ZnO}$ thin films through a He-Cd laser $(325 \mathrm{~nm})$. The optical transmittance was recorded by using a MP100-ME UV-VisNIR spectrophotometer and the wettability of $\mathrm{ZnO}$ thin films was also measured by contact angle meter, respectively.

As for UV photodetector fabrication, the interdigitated $\mathrm{Pt}$ (thickness $\sim 100 \mathrm{~nm}$ ) Ohmic contact electrode was fabricated via conventional UV lithography, wet-etching methods, and RF magnetron sputtering to form finger-pattern onto epitaxial $\mathrm{ZnO}$ (0002) films. The finger-pattern of the contact electrodes was $30 \mu \mathrm{m}$ wide (14pairs) and had an interelectrode spacing of $150 \mu \mathrm{m}$. The photo image of interdigitated electrode is shown in Figure 1. In order to form Ohmic contacts, $\mathrm{ZnO}$ and $\mathrm{Pt}$ would be directly connected. Unfortunately, the work functions of the above materials are not close, $5.65 \mathrm{eV}$ and $4.3 \mathrm{eV}$, respectively. For the sake of overcoming mismatch of work functions, the rapid thermal annealing (RTA) was used instead to form Ohmic contacts. Postannealing was performed at different temperatures between $350^{\circ} \mathrm{C}$ and $550^{\circ} \mathrm{C}$ for $10 \mathrm{~min}$ at argon and nitrogen ambients, respectively. The Ahilent HP 1456 S measurement system combined with a $38 \mathrm{~mW} / \mathrm{cm}^{2}$ mercury arc lamp (Hamamatsu-deuterium L2D2) was used as the UV $(365 \mathrm{~nm})$ light source to measure current-voltage $(I-V)$ characteristic and photoresponse, respectively. 


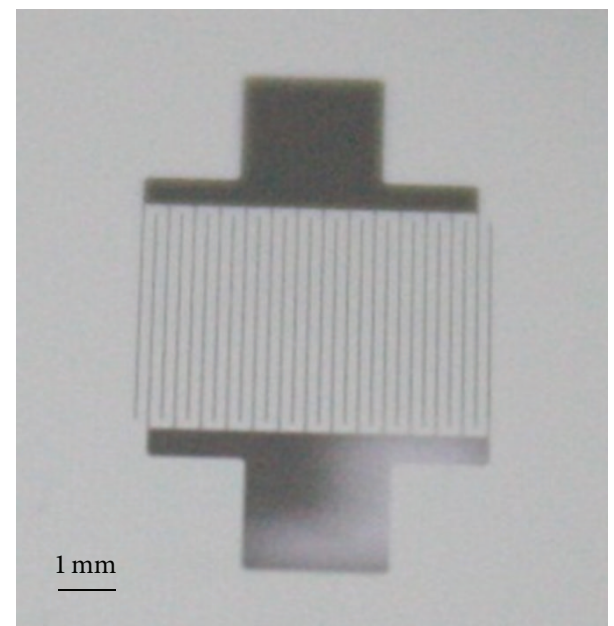

FIGURE 1: The photo image is for the interdigitated electrode.

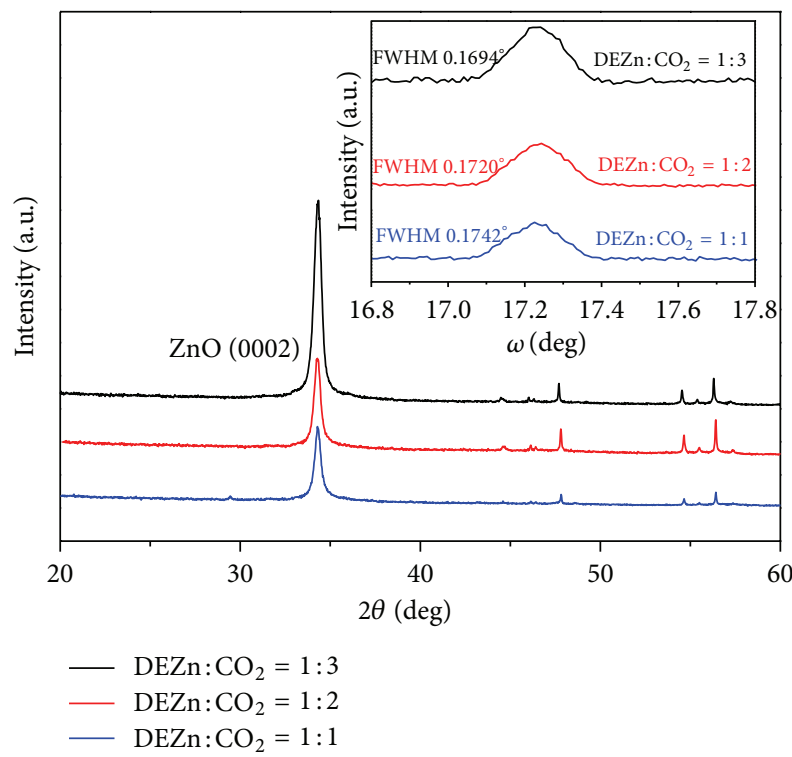

FIGURE 2: X-ray diffraction patterns for the $\mathrm{ZnO}$ (0002) thin films synthesized with different gas flow rate ratios of DEZn to $\mathrm{CO}_{2}$. Inset showed the corresponding rocking curve $(\omega)$ scan and FWHM values of $\mathrm{ZnO}$ (0002) peak.

\section{Results and Discussion}

3.1. Material Optimization. Figure 2 shows the X-ray diffraction (XRD) patterns for the $\mathrm{ZnO}$ thin films synthesized by PECVD system with different gas flow rate ratios of DEZn to $\mathrm{CO}_{2}$. The XRD patterns of all $\mathrm{ZnO}$ samples exhibit only a strong $c$-axis (0002) diffraction peak located at $34.4^{\circ}$, indicating that epitaxial thin films possess a hexagonal wurtzite structure. The lowest surface energy of the (0002) basal plane in $\mathrm{ZnO}$ leads to a preferred orientation in the [0001] direction; as a result, $\mathrm{ZnO}$ thin films have been grown with $c$-axis orientation onto epitaxial substrate under optimum growth conditions [24]. However, the crystalline quality of the $\mathrm{ZnO}$ thin films is related to the gas flow rate ratio of $\mathrm{DEZn}$ to $\mathrm{CO}_{2}$. During the $\mathrm{ZnO}$ phase growth, $\mathrm{CO}_{2}$ concentration played an important role due to the oxygen ions originating from $\mathrm{CO}_{2}$ which that were relatively low in the chamber when gas flow rate value was $1: 1$, which indicated the zinc ions had no sufficient chance to react with oxygen ions to form a high property $\mathrm{ZnO}$ phase. Consequently, with the increasing gas flow rate of $\mathrm{CO}_{2}$, the diffraction peak of the $\mathrm{ZnO}(0002)$ gradually became sharp and narrow. The strongest of (0002) diffraction peaks was obtained at the gas flow rate value of 1:3 (DEZn to $\left.\mathrm{CO}_{2}\right)$. The inset in Figure 2 showed the full width at half maximum (FWHM) of $\mathrm{ZnO}$ (0002) diffraction peak, which was determined by X-ray rocking curve $(\omega)$ scan. The FWHM of the (0002) diffraction peak of the $\mathrm{ZnO}$ thin film with gas flow rate ratio of $1: 3$ shows an extremely small value of $0.1694^{\circ}$, while the $\mathrm{ZnO}$ thin films with gas flow rate ratios of $1: 2$ and $1: 1$ exhibit relatively large values of $0.1720^{\circ}$ and $0.1742^{\circ}$, respectively. The X-ray rocking curve mostly demonstrates the degree of the tilt component, and the tilt itself is related to screw-type threading dislocations. Therefore, the optimum synthesized condition of epitaxial $\mathrm{ZnO}$ (0002) film with the gas flow rate ratio of DEZn to $\mathrm{CO}_{2}$ is $1: 3$ in this presented work. This parameter can effectively reduce screw dislocation density with the highest crystalline quality of stoichiometric $\mathrm{ZnO}$ thin film.

In-plane surface morphology of epitaxial $\mathrm{ZnO}$ (0002) films was observed by FE-SEM as shown in Figures 3(a)-3(c). PECVD system is a promising technique for synthesizing $\mathrm{ZnO}$ phase by using DEZn and $\mathrm{CO}_{2}$ mixtures. Also, it is especially easy to break the oxygen-oxygen bonds from $\mathrm{CO}_{2}$ to react with zinc atoms from DEZn, leading to the compact surface [25]. The SEM top view images clearly show that all of the $\mathrm{ZnO}$ thin films have smoothability of compact surfaces with curvature boundary and are densely packed with spherical grains. Additionally, the thickness of all $\mathrm{ZnO}$ thin films is about $500 \mathrm{~nm}$ with self-assembled columnar structures along the $c$-axis [0001] determined by cross section images in the inset of Figures 3(a)-3(c). From the AFM surface topography images as shown in Figures 3(d)-3(f), the average surface roughness values (root-mean-square (RMS) with the gas flow rate ratios of DEZn to $\mathrm{CO}_{2}(1: 1,1: 2$, and $1: 3)$ showed $6.46 \mathrm{~nm}, 6.82 \mathrm{~nm}$, and $8.97 \mathrm{~nm}(1 \mu \mathrm{m} \times 1 \mu \mathrm{m})$, respectively. The above results indicated that the epitaxial $\mathrm{ZnO}$ (0002) thin film could provide a suitable nanometerscale smoothness topography for the subsequent deposition of Pt top electrode onto its surface.

Figure 4 illustrates the room temperature PL spectrum. The spectra mainly consist of two emission bands: a nearband-edge (NBE) emission and a broad defect-related visible emission $(500-700 \mathrm{~nm})$. The result exhibits that the main emission bands intensity is closely related to the gas flow rate ratios of $\mathrm{DEZn}$ to $\mathrm{CO}_{2}$. All the epitaxial $\mathrm{ZnO}$ (0002) thin films show a strong NBE emission band which is attributed to the recombination of free-excitons through an excitonexciton collision process [26]. However, with varying the gas flow rate ratios of $\mathrm{DEZn}$ to $\mathrm{CO}_{2}$ (ranging from $1: 3$ to $1: 1$ ), the intensity of NBE emission became weaker with slight red shift, accompanied with the visible emission band became stronger. In general, the lattice distortions and localization of charges from interface defects or point defects may cause 




(a)

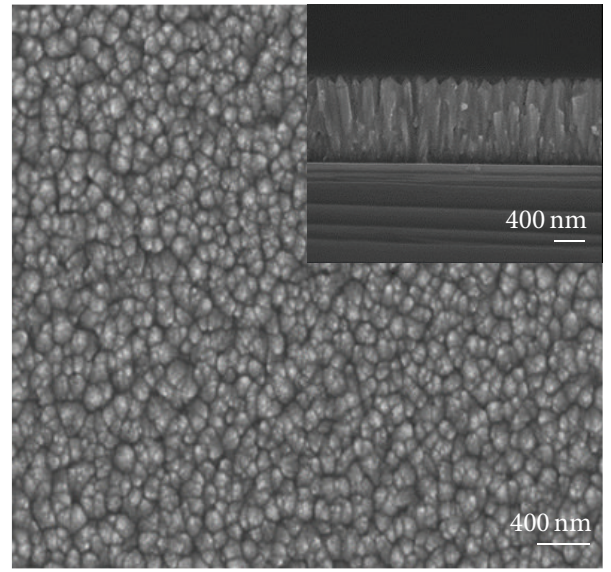

(b)

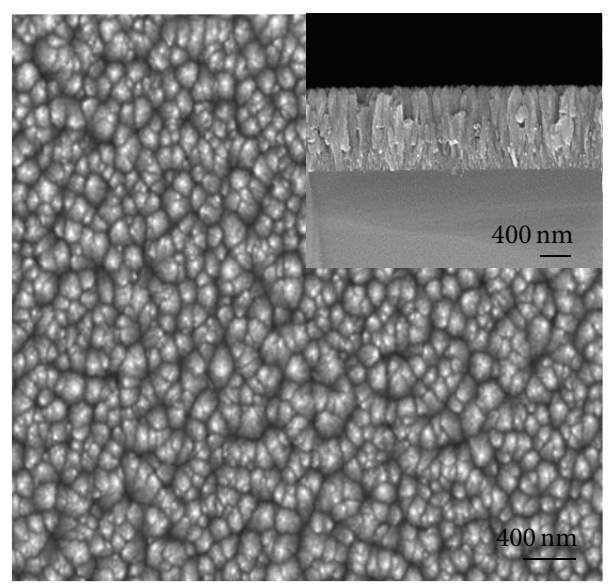

(c)



(d)

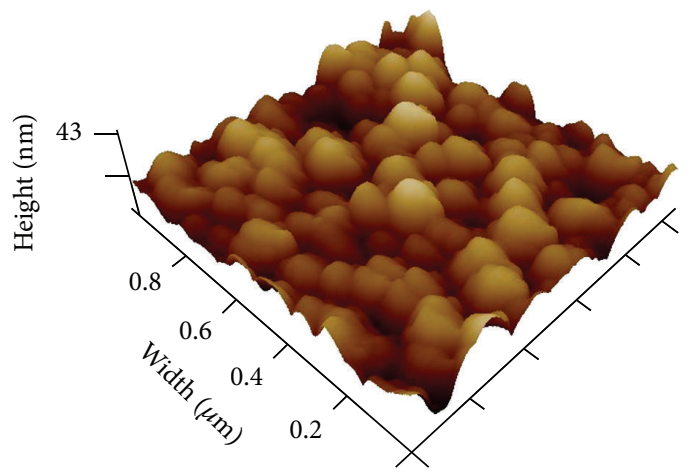

(e)

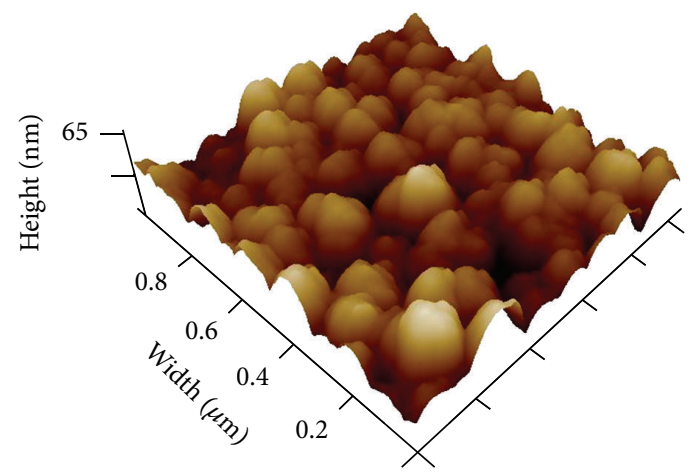

(f)

FIGURE 3: In-plane and out-of-plane field emission scanning electron microscopy images for $\mathrm{ZnO}(0002)$ thin films synthesized with gas flow rate ratios of DEZn to $\mathrm{CO}_{2}$ of (a) $1: 1$, (b) $1: 2$, and (c) $1: 3$; the corresponding AFM images $\left(1 \times 1 \mu \mathrm{m}^{2}\right)$ with gas flow rate ratios of (d) $1: 1$, (e) $1: 2$, and (f) $1: 3$, respectively.

the red shift of emission band [27]. On the other hand, the visible emission band is generally referred to the impurities and various structural defects in the $\mathrm{ZnO}$ thin films such as zinc interstitial and oxygen vacancy [28]. When thin film quality of $\mathrm{ZnO}$ was improved via providing sufficient oxygen ions, the density of defect was reduced and resulted in a strong intensity of NBE emission with blue shift in the UV region and the visible emission gradually disappeared. According to the above results, the epitaxial $\mathrm{ZnO}$ (0002) thin film grown under the optimum gas flow rate ratio of $1: 3\left(\mathrm{DEZn}\right.$ to $\left.\mathrm{CO}_{2}\right)$ 


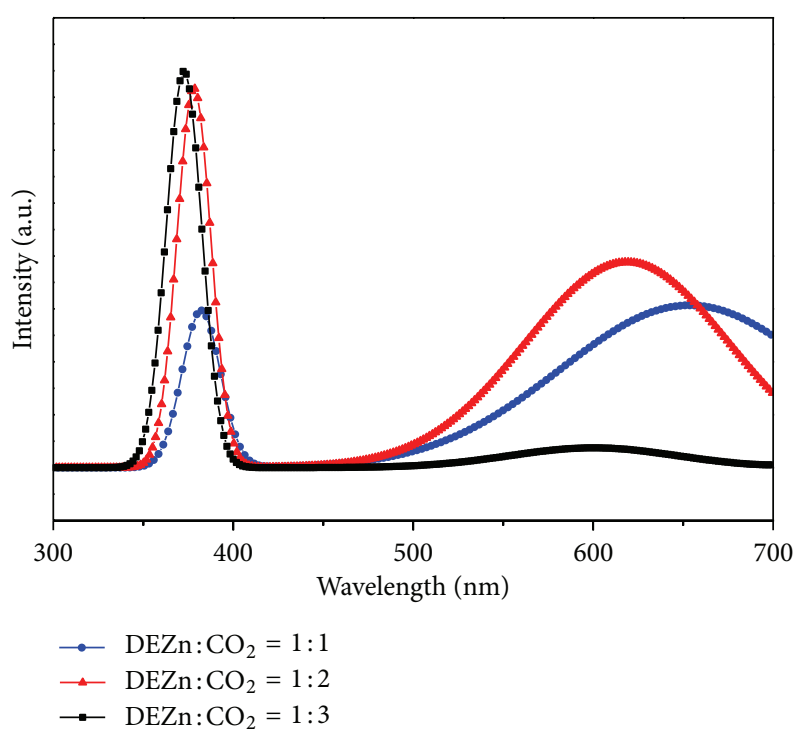

Figure 4: Photoluminescence spectra for the $\mathrm{ZnO}$ (0002) thin films synthesized with different gas flow rate ratios of DEZn to $\mathrm{CO}_{2}$.

is a promising approach for application in the realization of ultraviolet (UV) photon detectors.

3.2. UV Photodetector Fabrication and Responsivity. Currentvoltage $(I-V)$ characteristics of the $\mathrm{Pt} / \mathrm{ZnO}$ nanobilayer devices annealed at various temperatures $\left(350^{\circ} \mathrm{C}, 450^{\circ} \mathrm{C}\right.$, and $550^{\circ} \mathrm{C}$ ) in argon ambience for $10 \mathrm{~min}$ are shown in Figure 5(a). Only an obvious linear behavior could be observed for the $\mathrm{Pt} / \mathrm{ZnO}$ device annealed at $450^{\circ} \mathrm{C}$, which indicated that the high quality Ohmic contact has been achieved at the $\mathrm{Pt} / \mathrm{ZnO}$ interface. The device was further annealed at $450^{\circ} \mathrm{C}$ in nitrogen ambience for $10 \mathrm{~min}$, and corresponding $I-V$ characteristics of device were as shown in Figure 5(b). The Ohmic effect of $\mathrm{Pt} / \mathrm{ZnO}$ device annealed in nitrogen ambience shows better performance than that of annealing in argon ambience. The schematic diagram for the UV photodetector device is shown in the inset of Figure 5(a), in which interdigitated $\mathrm{Pt}$ electrode was deposited onto the optimal $\mathrm{ZnO}$ (0002) thin films. The formation of thermally stable and low resistance Ohmic contacts is critical to realizing high quality $\mathrm{ZnO}$-based optoelectronic devices. The high contact resistance between semiconductor and metal gives rise to the degradation of optoelectronic device performance through thermal stress and contact failure. Thermally stable and low contact resistance can be achieved either by performing surface modification to reduce the semiconductor-metal barrier height or by increasing the effective carrier concentration of the surface, which allow an increase in carrier tunnelling probability. Hence, Ohmic contact metallization should be one of the main purposes in improving the optoelectronic device performance. However, the formation of Ohmic contact method in $\mathrm{ZnO}$-based optoelectronic device has not been investigated extensively, and it is limited mostly to n-type contacts.
Figure 6 shows the dark current and photocurrent characteristics of the UV photodetector as a function of bias voltage ranged from $-5 \mathrm{~V}$ to $5 \mathrm{~V}$ for $\mathrm{Pt} / \mathrm{ZnO}$ thin films structure. It can be seen that only the $\mathrm{Pt} / \mathrm{ZnO}$ device annealed in argon ambience exhibits the photoconductive behavior as shown in Figure 6(a). Furthermore, both the dark and photo currents increase linearly with increasing bias voltage, indicating that the Pt top electrode forms the Ohmic contact onto the $\mathrm{ZnO}$ (0002) thin film. Without UV light illumination, the observed dark current was about $4.8 \mathrm{~mA}$ at a $5 \mathrm{~V}$ bias. When the $\mathrm{Pt} / \mathrm{ZnO}$ device was illuminated under a $365 \mathrm{~nm}$ wavelength with the energy of $38 \mathrm{~mW} / \mathrm{cm}^{2}$, the photocurrent was approximately $36 \mathrm{~mA}$ at a $5 \mathrm{~V}$ bias, indicating that the UV photodetector composed of $\mathrm{Pt} / \mathrm{ZnO}$ nanobilayer films structure has high photoresponsivity. The origin of photocurrent by the adsorption and desorption of oxygen molecules has been highly considered [29, 30]. Before UV illumination, the $\mathrm{ZnO}$ films were exposed to air in the dark and oxygen molecules, which could be adsorbed on the $\mathrm{ZnO}$ surface in order to extract free electrons according to the following:

$$
\begin{gathered}
\mathrm{O}_{2}(\mathrm{~g})+\mathrm{e}^{-} \longrightarrow \mathrm{O}_{2}{ }^{-}(\mathrm{ad}) \\
\mathrm{O}_{2}(\mathrm{~g})+2 \mathrm{e}^{-} \longrightarrow \mathrm{O}_{2}{ }^{2-}(\mathrm{ad})
\end{gathered}
$$

The negative oxygen ions adhered to the surface and created a depletion of electron at the grain boundaries of $\mathrm{ZnO}$ thin films. These negative oxygen ions cannot contribute to the conductivity to the thin film, which makes the thin film produce a low conductive surface. However, upon exposure to UV irradiation, the negative oxygen ions can form neutral by capturing a photogenerated hole, which is expressed in the following:

$$
\begin{aligned}
& \mathrm{H}^{+}+\mathrm{O}_{2}{ }^{-}(\mathrm{ad}) \longrightarrow \mathrm{O}_{2}(\mathrm{~g}) \\
& 2 \mathrm{H}^{+}+\mathrm{O}_{2}{ }^{2-}(\mathrm{ad}) \longrightarrow \mathrm{O}_{2}(\mathrm{~g})
\end{aligned}
$$

The wavelength of UV light $\sim 365 \mathrm{~nm}$ closely matches the band gap of $\mathrm{ZnO} \sim 3.37 \mathrm{eV}$; high energy photons get absorbed by the $\mathrm{ZnO}$ layer and generate electron-hole pairs consequently. The photogenerated holes recombine with electrons of the adsorbed oxygen ions through surface recombination and simultaneously release oxygen atoms from the surface. As a result, lowering of depletion layer height at the grain boundary region takes place. These accumulated unpaired electrons in the conduction band of $\mathrm{ZnO}$ will contribute to increasing the photoconductivity of the $\mathrm{ZnO}$-based UV devices.

The dark current and photocurrent characteristics of UV photodetector composed of $\mathrm{Pt} / \mathrm{ZnO}$ nanobilayer films structure annealed in nitrogen are also shown in Figure 6(b). The $I-$ $V$ characteristics of dark and photo-currents are overlapping, which means the device has no photoresponsivity. When the $\mathrm{Pt} / \mathrm{ZnO}$ films structure was annealed in nitrogen ambience, the nitrogen atoms might not only act as acceptors and form a doped layer near the surface of the $\mathrm{ZnO}$ thin film but also produce a thin nitride layer. The increase in the carrier concentration with the nitride layer can lower the barrier 


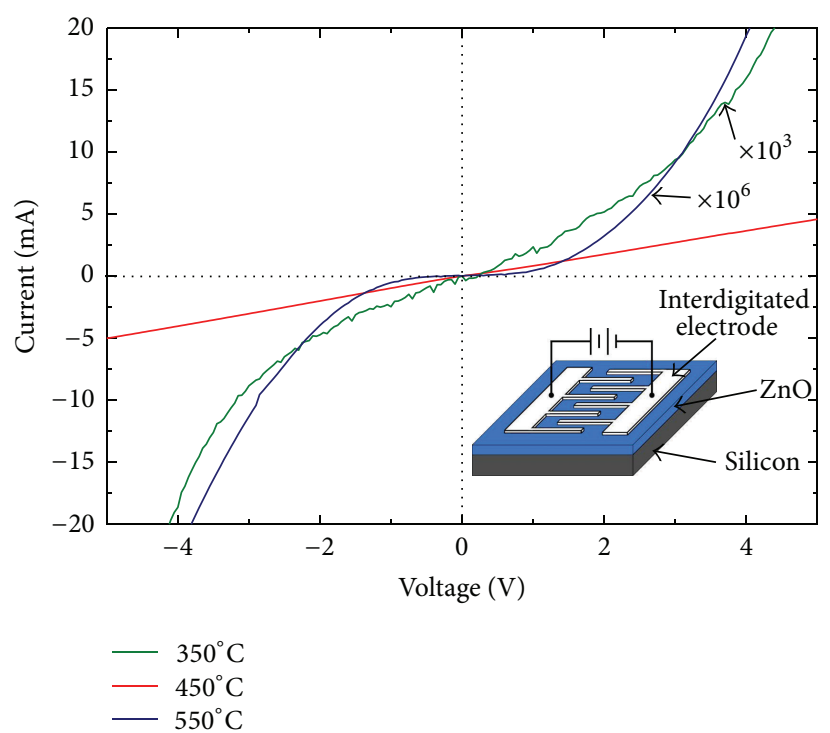

(a) Annealing in argon ambience



(b) Annealing in argon and nitrogen ambients

FIGURE 5: (a) Current-voltage ( $I-V)$ characteristic of the ultraviolet (UV) photodetector with $\mathrm{Pt} / \mathrm{ZnO}$ nanobilayer films structure annealed in argon ambience at different temperatures $\left(350^{\circ} \mathrm{C}, 450^{\circ} \mathrm{C}\right.$, and $\left.550^{\circ} \mathrm{C}\right)$, and the inset showed the schematic structure of UV photodetector device. (b) The dark $I-V$ characteristic of the $\mathrm{Pt} / \mathrm{ZnO}$ nanobilayer structure annealed at $450^{\circ} \mathrm{C}$ in argon and nitrogen ambients, respectively.

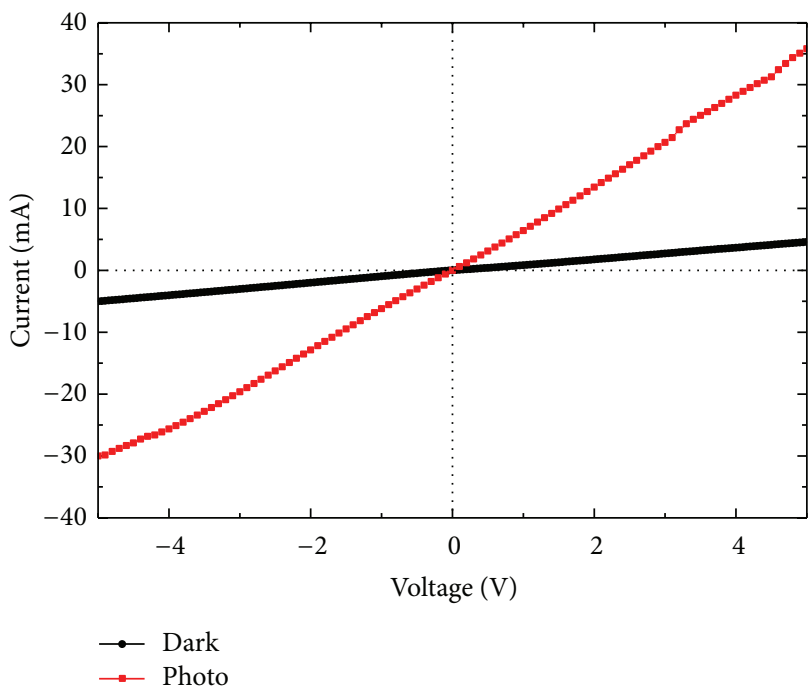

(a) Argon

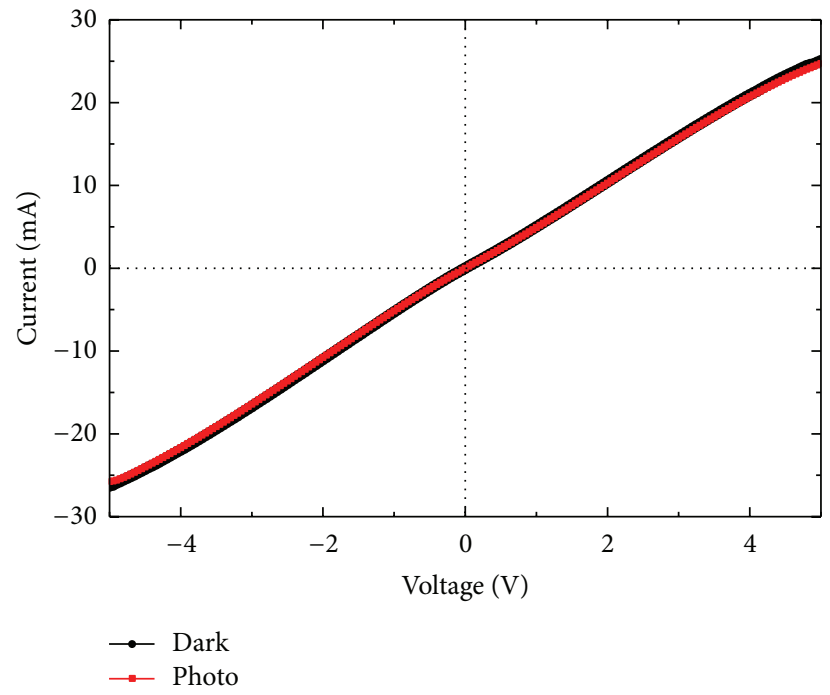

(b) Nitrogen

FIgURE 6: The dark current and photocurrent characteristics for the UV photodetector composed of Pt/ZnO nanobilayer films structure annealed in (a) argon and (b) nitrogen ambients, respectively.

height of the Ohmic contact, which was formed between the Pt electrode and $\mathrm{ZnO}$ thin film. It will lead to higher current value with lower resistance compared with the device annealed in argon ambience. At the same time, the nitride layer onto the $\mathrm{ZnO}$ thin film surface would directly prevent UV light irradiation for the surface of $\mathrm{ZnO}$ thin film. Hence, the aforementioned electric filed generated from the depletion region of the $\mathrm{ZnO}$ thin film surface will be forbidden. The UV photodetector device composed of $\mathrm{Pt} / \mathrm{ZnO}$ bilayer films structure annealed in nitrogen ambience is not suitable for UV sensor owing to the lack of photoconductivity.

The reproducibility of the photodetector device annealed in argon ambience was tested by repeatedly switching UV light on and off for the same time intervals as shown in Figure 7. When the device was illuminated by the UV light, the current increased sharply and remained in a stable state. After the removal of light source, the device recovered to an original level. The response and recovery times of the device 


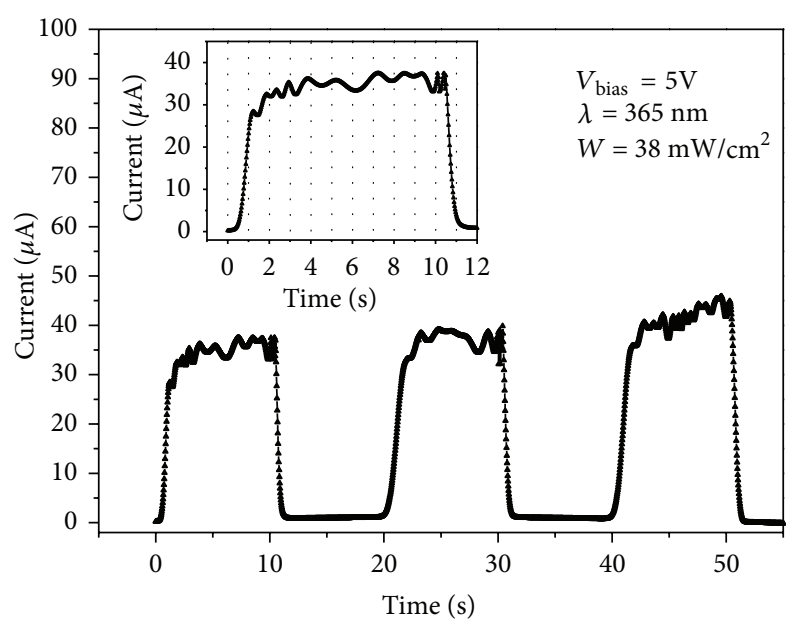

FIgURE 7: Photocurrent as a function of measured time obtained by switching on and off UV illumination on the photodetector composed of $\mathrm{Pt} / \mathrm{ZnO}$ nanobilayer films structure.

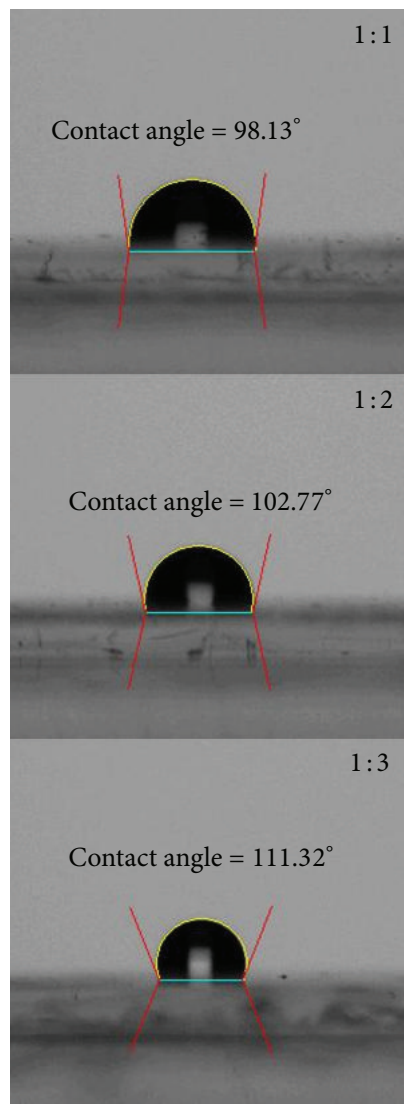

Figure 8: Water contact angle images accompanied with the measured values for the $\mathrm{ZnO}$ (0002) thin films synthesized at different gas flow rate ratios of DEZn to $\mathrm{CO}_{2}$.

are $2 \mathrm{~s}$ and $1.5 \mathrm{~s}$, respectively, as shown in the inset of Figure 7. The result shows great reproducibility and good stability for the UV photodetector device at least 3 times without change. The quick response and stability obtained from the device are useful for UV photodetector application.

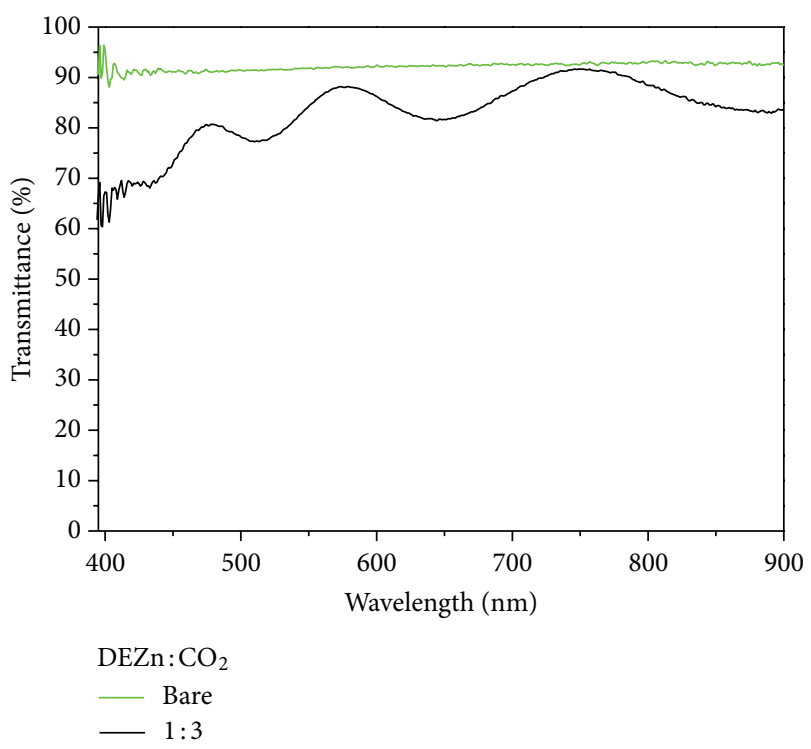

FIGURE 9: Optical transmittance spectra for the $\mathrm{ZnO}$ (0002) thin film synthesized at gas flow rate ratio of $1: 3$ compared with the bare glass substrate.

On the other hand, the wettability of epitaxial $\mathrm{ZnO}(0002)$ thin films was characterized by a contact angle goniometer (Pentad FTA 125). If the water contact angle with the surface is smaller than $90^{\circ}$, then the surface is termed as hydrophilic. On the contrary, if the water contact angle with the surface is greater than $90^{\circ}$ then the surface is termed as hydrophobic. Figure 8 shows the water contact angle values of $\mathrm{ZnO}$ films with various gas flow rate ratios of $1: 1,1: 2$, and $1: 3$ are $98.13^{\circ}, 102.77^{\circ}$, and $111.32^{\circ}$, respectively. In general, the high hydrophobic property was formed by modifying surfaces with low surface energy coating [31] or increasing surface roughness [32]. In our presented work, the measured results indicated that the surface of $\mathrm{ZnO}$ thin films was more hydrophobic with increasing surface roughness. Compared with the water contact angle values of $\mathrm{ZnO}$ films with various gas flow rate ratios, the largest surface roughness was obtained with the gas flow rate ratio of $1: 3(8.97 \mathrm{~nm})$, leading to the largest hydrophobicity consistent with the observed results from Figure 3 .

Additionally, in order to investigate the transparency of epitaxial $\mathrm{ZnO}$ (0002) thin film, the $\mathrm{ZnO}$ (0002) thin film was also synthesized onto glass substrates for future high-transmittance $\mathrm{ZnO}$-based optoelectronic devices. The transmittance spectrum showed that $\mathrm{ZnO}$ (0002) thin film exhibits high transmittance in the $400-900 \mathrm{~nm}$ range and with higher than $80 \%$ visible transmittance as shown in Figure 9 .

\section{Conclusions}

Epitaxial $\mathrm{ZnO}(0002)$ thin film was at first synthesized on silicon substrate with gas flow rate ratio of $1: 3\left(\mathrm{DEZn}\right.$ to $\left.\mathrm{CO}_{2}\right)$ by PECVD system, which exhibited good crystallinity, low surface roughness, high optical properties, and good visible 
transparency. The Ohmic contacts were formed between $\mathrm{Pt}$ top electrode and $\mathrm{ZnO}$ thin films together annealed at $450^{\circ} \mathrm{C}$ in argon and nitrogen ambients for $10 \mathrm{~min}$. However, the UV photodetector composed of $\mathrm{Pt} / \mathrm{ZnO}$ nanobilayers structure only annealed in argon ambience shows a lower dark current of $4.8 \mathrm{~mA}$ and a higher photocurrent of $36 \mathrm{~mA}$ at $5 \mathrm{~V}$ bias voltage. Therefore, a simple method is presented which used Pt contact electrode onto epitaxial $\mathrm{ZnO}$ (0002) thin film and is suitable for potential device application of UV photodetector, showing a good Ohmic contacts behavior as well as UV photoresponsibility.

\section{Conflict of Interests}

The authors declare that there is no conflict of interests regarding the publication of this paper.

\section{Acknowledgments}

The authors acknowledge financial support of the main research project of the National Science Council of Taiwan under Grant no. NSC 101-2221-E-027-042.

\section{References}

[1] M.-L. Tu, Y.-K. Su, S.-J. Chang, and R. W. Chuang, "GaN UV photodetector by using transparency antimony-doped tin oxide electrode," Journal of Crystal Growth, vol. 298, pp. 744-747, 2007.

[2] G. Hellings, J. John, A. Lorenz, P. Malinowski, and R. Mertens, "AlGaN schottky diodes for detector applications in the UV wavelength range," IEEE Transactions on Electron Devices, vol. 56, no. 11, pp. 2833-2839, 2009.

[3] T. K. Lin, S. J. Chang, Y. K. Su et al., "ZnSe MSM photodetectors prepared on GaAs and ZnSe substrates," Materials Science and Engineering B, vol. 119, no. 2, pp. 202-205, 2005.

[4] Y. Iwakaji, M. Kanasugi, O. Maida, and T. Ito, "Characterization of diamond ultraviolet detectors fabricated with high-quality single-crystalline chemical vapor deposition films," Applied Physics Letters, vol. 94, no. 22, Article ID 223511, 2009.

[5] C. H. Chen, "GaN-based metal-insulator-semiconductor ultraviolet photodetectors with $\mathrm{HfO}_{2}$ insulators," Japanese Journal of Applied Physics, vol. 528, part 2, Article ID 08JF08, 2013.

[6] J. Zhang and S. Sakai, "Optical properties characterization of InGaN/GaN near UV photodetector with surface nanostructure fabricated by nano-imprinting," Advanced Materials Research, vol. 399-401, pp. 629-634, 2012.

[7] T. T. Guo, G. B. Dong, F. Y. Gao, Y. Xiao, Q. Chen, and X. G. Diao, "High performance $\mathrm{ZnO}$ :Al films deposited on PET substrates using facing target sputtering," Applied Surface Sceeince, vol. 282, p. 467, 2013.

[8] L. Q. Zhang, B. Liu, Y. H. Lu et al., "Non-polar p-type $\mathrm{Zn}_{0.94} \mathrm{Mn}_{0.05} \mathrm{Na}_{0.01} \mathrm{O}$ texture: growth mechanism and codoping effect," Journal of Applied Physics, vol. 113, Article ID 083513, 2013.

[9] X.-L. Guo, H. Tabata, and T. Kawai, "Pulsed laser reactive deposition of p-type $\mathrm{ZnO}$ film enhanced by an electron cyclotron resonance source," Journal of Crystal Growth, vol. 223, no. 1-2, pp. 135-139, 2001.

[10] Q. A. Xu, J. W. Zhang, K. R. Ju, X. D. Yang, and X. Hou, "ZnO thin film photoconductive ultraviolet detector with fast photoresponse," Journal of Crystal Growth, vol. 289, no. 1, pp. 44-47, 2006.

[11] D. Basak, G. Amin, B. Mallik, G. K. Paul, and S. K. Sen, "Photoconductive UV detectors on sol-gel-synthesized $\mathrm{ZnO}$ films," Journal of Crystal Growth, vol. 256, no. 1-2, pp. 73-77, 2003.

[12] A. Y. Polyakov, N. B. Smirnov, A. V. Govorkov et al., "Persistent photoconductivity in p-type $\mathrm{ZnO}(\mathrm{N})$ grown by molecular beam epitaxy," Applied Physics Letters, vol. 90, no. 13, Article ID 132103, 2007.

[13] W. Yang, R. D. Vispute, S. Choopun, R. P. Sharma, T. Venkatesan, and H. Shen, "Ultraviolet photoconductive detector based on epitaxial $\mathrm{Mg}_{0.34} \mathrm{Zn}_{0.66} \mathrm{O}$ thin films," Applied Physics Letters, vol. 78, no. 18, pp. 2787-2789, 2001.

[14] X.-Y. Liu, Y.-A. Li, S. Liu, H.-L. Wu, and H.-N. Cui, " $\mathrm{ZnO} / \mathrm{Cu} / \mathrm{ZnO}$ multilayer films: structure optimization and investigation on photoelectric properties," Thin Solid Films, vol. 520, no. 16, pp. 5372-5377, 2012.

[15] B. Liu, T. T. Zhou, M. G. Ma et al., "Realization of non c-axis oriented $\mathrm{ZnO}$ thin films on quartz through $\mathrm{Mn}$-Li co-doping," Materials Letters, vol. 108, p. 153, 2013.

[16] H. C. Park, D. Byun, B. Angadi et al., "Photoluminescence of $\mathrm{Ga}$-doped $\mathrm{ZnO}$ film grown on $\mathrm{c}-\mathrm{Al}_{2} \mathrm{O}_{3}$ (0001) by plasmaassisted molecular beam epitaxy," Journal of Applied Physics, vol. 102, no. 7, Article ID 073114, 2007.

[17] A. Marzouki, A. Lusson, F. Jomard et al., "SIMS and Raman characterizations of $\mathrm{ZnO}: \mathrm{N}$ thin films grown by MOCVD," Journal of Crystal Growth, vol. 312, no. 21, pp. 3063-3068, 2010.

[18] M. Macias-Montero, A. Borras, Z. Saghi et al., "Vertical and tilted Ag-NPs@ZnO nanorods by plasma-enhanced chemical vapour deposition," Nanotechnology, vol. 23, no. 25, Article ID 255303, 2012.

[19] M. D. Barankin, E. Gonzalez II, A. M. Ladwig, and R. F. Hicks, "Plasma-enhanced chemical vapor deposition of zinc oxide at atmospheric pressure and low temperature," Solar Energy Materials and Solar Cells, vol. 91, no. 10, pp. 924-930, 2007.

[20] J. S. Wright, R. Khanna, K. Ramani et al., "ZrB2/Pt/Au Ohmic contacts on bulk, single-crystal ZnO," Applied Surface Science, vol. 253, no. 5, pp. 2465-2469, 2006.

[21] J.-M. Lee, K.-K. Kim, S.-J. Park, and W.-K. Choi, "Lowresistance and nonalloyed ohmic contacts to plasma treated ZnO," Applied Physics Letters, vol. 78, no. 24, pp. 3842-3844, 2001.

[22] J.-M. Lee, K.-K. Kim, H. Tampo, A. Yamada, and S. Niki, "Ohmic contact behavior of $\mathrm{Pt} / \mathrm{Ni} / \mathrm{Au}$ to $\mathrm{p}-\mathrm{ZnO}$," in $2006 \mathrm{MRS}$ Spring Meeting, pp. 50-55, usa, April 2006.

[23] Y. F. Lu, Z. Z. Ye, Y. J. Zeng, L. P. Zhu, J. Y. Huang, and B. H. Zhao, "Low-resistivity Ni/Pt Ohmic contacts to p-type N-doped ZnO," Solid-State Electronics, vol. 54, no. 7, pp. 732-735, 2010.

[24] N. Fujimura, T. Nishihara, S. Goto, J. Xu, and T. Ito, "Control of preferred orientation for $\mathrm{ZnO}_{x}$ films: control of self-texture," Journal of Crystal Growth, vol. 130, no. 1-2, pp. 269-279, 1993.

[25] Z. Z. Zhi, Y. C. Liu, B. S. Li et al., "Effects of thermal annealing on $\mathrm{ZnO}$ films grown by plasma enhanced chemical vapour deposition from $\mathrm{Zn}\left(\mathrm{C}_{2} \mathrm{H}_{5}\right)_{2}$ and $\mathrm{CO}_{2}$ gas mixtures," Journal of Physics D, vol. 36, no. 6, pp. 719-722, 2003.

[26] S. H. Bae, S. Y. Lee, H. Y. Kim, and S. Im, "Effects of postannealing treatment on the light emission properties of $\mathrm{ZnO}$ thin films on Si," Optical Materials, vol. 17, no. 1-2, pp. 327-330, 2001. 
[27] C. L. Yang, J. N. Wang, W. K. Ge, L. Guo, S. H. Yang, and D. Z. Shen, "Enhanced ultraviolet emission and optical properties in polyvinyl pyrrolidone surface modified $\mathrm{ZnO}$ quantum dots," Journal of Applied Physics, vol. 90, no. 9, pp. 4489-4493, 2001.

[28] B. Lin, Z. Fu, and Y. Jia, "Green luminescent center in undoped zinc oxide films deposited on silicon substrates," Applied Physics Letters, vol. 79, no. 7, pp. 943-945, 2001.

[29] C. Soci, A. Zhang, B. Xiang et al., "ZnO nanowire UV photodetectors with high internal gain," Nano Letters, vol. 7, no. 4, pp. 1003-1009, 2007.

[30] H. Kind, H. Yan, B. Messer, M. Law, and P. Yang, "Nanowire ultraviolet photodetectors and optical switches," Advanced Materials, vol. 14, pp. 158-160, 2002.

[31] A. Nakajima, K. Hashimoto, T. Watanabe, K. Takai, G. Yamauchi, and A. Fujishima, "Transparent superhydrophobic thin films with self-cleaning properties," Langmuir, vol. 16, no. 17, pp. 7044-7047, 2000.

[32] X. Feng, L. Feng, M. Jin, J. Zhai, L. Jiang, and D. Zhu, "Reversible super-hydrophobicity to super-hydrophilicity transition of aligned $\mathrm{ZnO}$ nanorod films," Journal of the American Chemical Society, vol. 126, no. 1, pp. 62-63, 2004. 

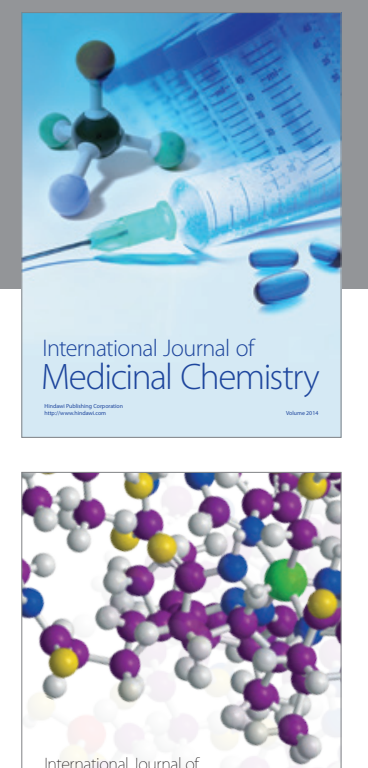

\section{Carbohydrate} Chemistry

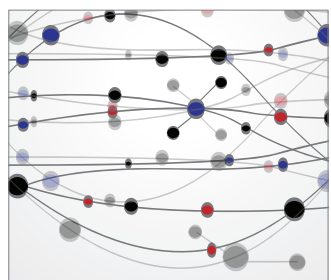

The Scientific World Journal
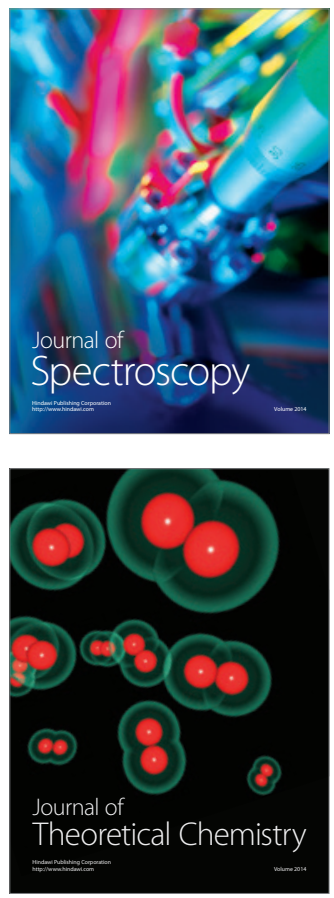


Submit your manuscripts at

http://www.hindawi.com

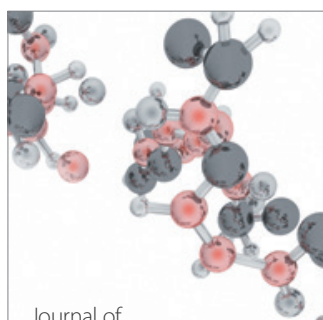

Analytical Methods

in Chemistry

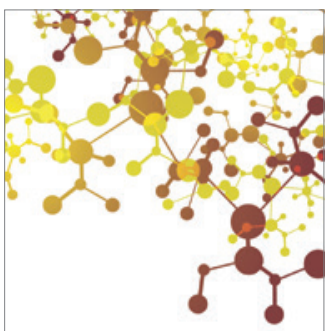

Journal of

Applied Chemistry

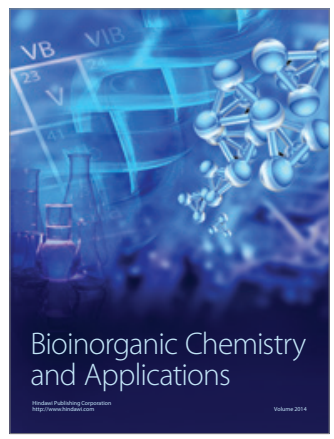

Inorganic Chemistry
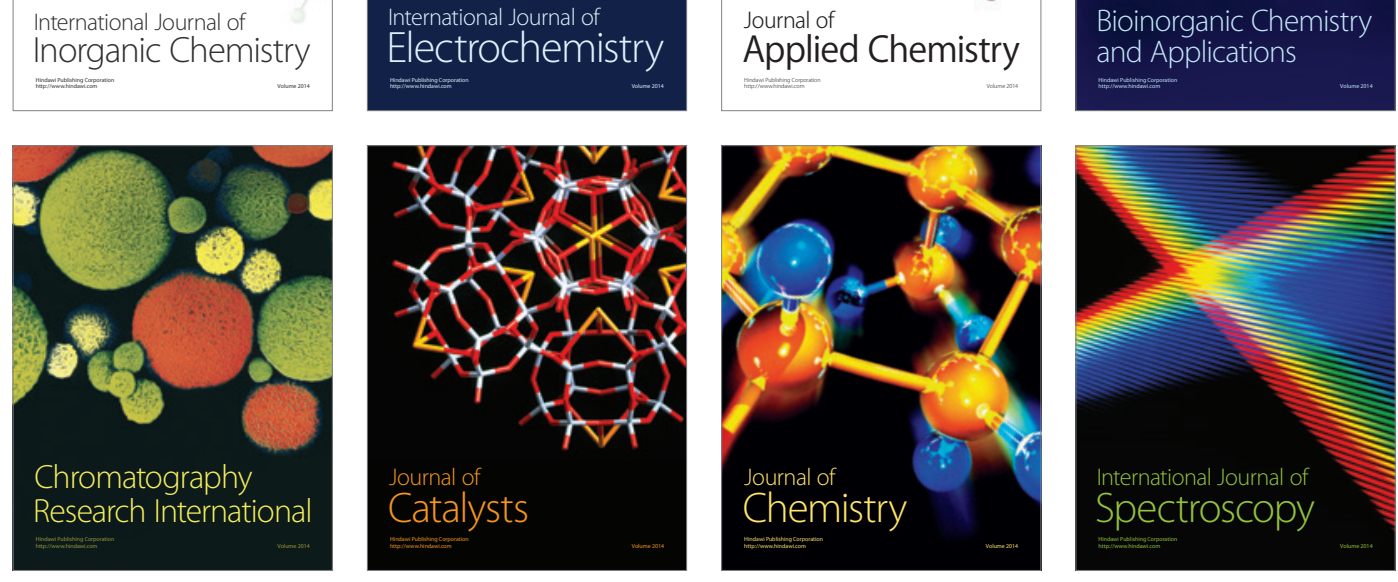